\title{
Prediction and measurement of the aerodynamic performance of a wind turbine
}

\author{
Ali Cemal Benim*, Michael Diederich, and Fethi Gül \\ Center of Flow Simulation (CFS), Department of Mechanical and Process Engineering, Düsseldorf University of Applied Sciences, \\ Münsterstr. 156, D-40476 Düsseldorf, Germany
}

\begin{abstract}
Aerodynamic behavior of a small wind turbine is analyzed, both experimentally and numerically. Mainly, an unsteady three-dimensional formulation is adopted, where the flow turbulence is modelled by an Improved Delayed Detached Eddy Simulation framework, using the four-equation transitional Shear Stress Transport model, as the turbulence model. A quite good agreement between the measurements and calculations is observed.
\end{abstract}

\section{Introduction}

Wind energy is increasingly occupying an important position in power generation from the renewable energy resources.

Apart from the large-sized wind turbines with large capacities (MW range), which can be installed on-shore or off-shore, small-sized wind turbines with relatively small capacities (approximately $10 \mathrm{~kW}$ and smaller) are being increasingly installed in urban regions, for a much wider and more thorough usage of the wind energy.

Small wind turbines are also significant for decentralized power generation and power autarchy. A serious problem pertaining the usage of small wind turbines in urban regions is noise generation, which is also an issue in the project in which the present study is imbedded.

Unsteady, three-dimensional calculations, along with experiments are conducted for an available small, horizontal-axis wind turbine power plant.

Flow turbulence is modelled by applying highresolution methods [1-3] that will be discussed in more detail below.

Amongst the considerable number of the previous analyses on the aerodynamics of the wind turbines, there is a large number of investigations that deal with the aerodynamic optimization [4].

However, the larger number of those investigations adopt rather simplified approaches, such as the Blade Element Momentum (BEM) methodology for predicting the flow field.

Investigations that apply a CFD approach [5-7] are rather smaller in number, where comparably simpler, i.e. one-equation turbulence models were used. In the present work, a more accurate turbulence modelling is applied.

\section{The investigated wind power plant}

The investigated wind power plant is a small, horizontal axis wind turbine with three rotor blades and a nominal electrical power of $12 \mathrm{~kW}$. The wind power plant is installed near Husum, in northern Germany and in operation. The pole has the height of approximately 30 $\mathrm{m}$. The nominal rotor speed is 2 revolutions within a second. The wind speed and the electrical power output of the power plant has been continuously monitored.

\section{Modelling approach}

The CFD analyses are conducted within the framework of the finite volume method based general-purpose CFD software ANSYS Fluent [8].

The Navier-Stokes equations, which are coupled with the equation of continuity are numerically solved, coupled with the equations of the turbulence model, as will be described below. For the material properties, constant values are used that correspond to those of air at air ambient conditions. It is assumed that the flow is incompressible. This can be deemed as realistic at the occurring velocities, which lead to maximum Mach numbers lower than 0.2 .

A three-dimensional modelling is applied. Here, the problem is defined in a rotating frame of reference, which is a typical procedure in the mathematical modelling of flows in turbomachinery [9-11].

In the three-dimensional, unsteady CFD calculations, a recent version of the DES, i.e. the Improved Delayed Detached Eddy Simulation (IDDES) $[8,12]$ is applied to model the turbulence, which is a hybrid RANS-LES approach.

As the RANS complementary, the four-equation transitional SST model $[8,13]$ is adopted to consider the transitional effects in the boundary layer, which was also previously used successfully in the prediction of

\footnotetext{
* Corresponding author: alicemal@prof-benim.com
} 
different categories of problems [14]. In preliminary calculations, which were also performed as part of grid independence studies, steady-state (RANS) modelling is also applied. Here, the two-equation SST $[8,15]$ model is adopted as the turbulence model, which has also previously been successfully used in a wide range of wall driven turbulent shear flows [16-20].

In the unsteady calculations, a second-order accurate backward differencing scheme is adopted for the time discretization.

The time step sizes are chosen in such a way that the cell Courant numbers remain smaller than unity. For the discretization in space, the central and second-order upwind schemes are used in a combined manner depending on the local turbulence formulation within the framework of the hybrid (LES/RANS) turbulence modelling approach. The velocity-pressure coupling is formulated by the PISO algorithm [8].

\section{Results}

In the computational modelling, the effect of the pole and the ground are omitted, since the associated additional computational effort would explode available framework.

At the outlet boundary, a constant static pressure together with vanishing normal gradients for the convectively transported variables are prescribed as boundary condition.

The boundary condition at the inlet boundary is defined to be, a prescribed uniform velocity field parallel to the turbine axis is prescribed together with a uniform turbulence intensity of $4 \%$ and a length scale equal to $25 \%$ of average chord length of the turbine blade. As the value of the constant wind velocity at the inlet boundary, $9.5 \mathrm{~m} / \mathrm{s}$ is prescribed (in stationary frame of references).

A formal grid independence study for the unsteady, three dimensional calculations using the IDDES turbulence model has not been performed within the present investigation. Grid independence studies were conducted as a preliminary study, using RANS models, in steady-state, which have led to design of the final three-dimensional grid, as also guided by the previous applications [9-11].

The computational grid is generated by an unstructured methodology, using tetrahedral cells. However, along the solid walls, the local grid is generated by using prism layers, for a better resolution of the boundary layer.

For arriving at an favorable distribution of the grid cells, the fact has been taken into account that the power generation takes place at rather high radial positions of the blade, where the local velocities are comparably high, whereas the radially lower parts of the blade do not considerably contribute to the power generation, in comparison, but are responsible, rather, for the stability of the blade construction.

Based on this consideration, the radially upper part of the blade is discretized by a finer grid resolution compared to its lower part. The finally applied computational grid consisted of approximately 6 million nodes. A view of the surface grid near the tip region is displayed in Fig. 1.

The predicted distribution of the time-averaged static pressure field around the blade, as well as the "pseudo streamlines" of the time-averaged velocity field in the rotating frame of reference are illustrated in Figure 2 for a constant-radius cross section along the height of the blade.

Please note that the displayed streamlines in Figure 2 are not the "real" streamlines. They are based on the two-dimensional velocity field that is obtained by the projection of the predicted three-dimensional velocity field onto the displayed plane of the considered blade section. Thus, they don't deliver the exact information on the flow field, as, for example, the mass flow rate conservation between neighboring streamlines is not guaranteed. Still, the flow structure can reasonably be visualized by means of the pseudo streamlines, where a local recirculation zone on the suction surface, near the trailing edge, can be observed.

The calculated aerodynamic efficiency for the conversion of the accessible wind power to the power on the shaft $\left(\eta_{a, p r e d}\right)$, as well as these measured efficiency for the conversion of the accessible wind power to the electrical power $\left(\eta_{e, \text { meas }}\right)$ are given in Table 1 .

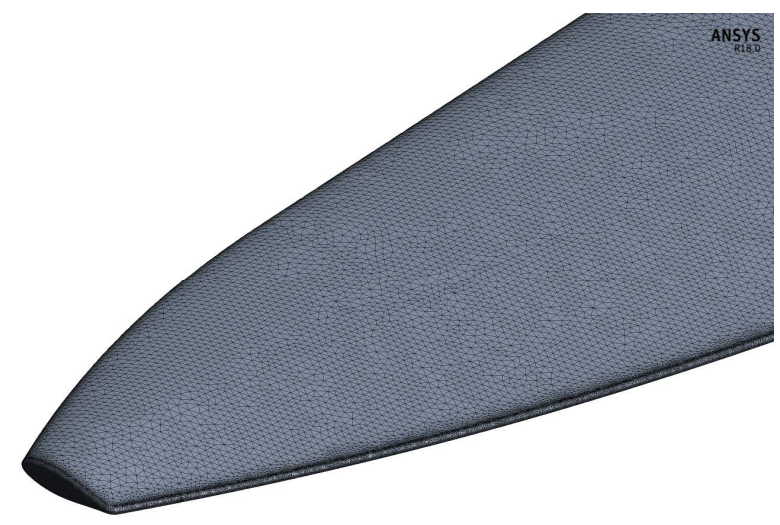

Fig. 1. A view of the surface grid near the tip.

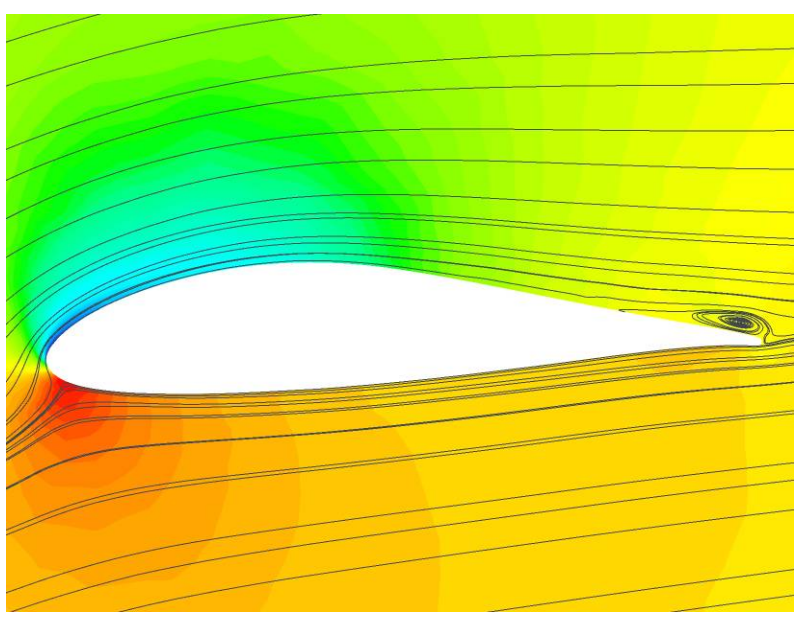

Fig. 2. Distribution of the time-averaged static pressure field and "pseudo streamlines" at a constant-radius section. 
Table 1. Efficiencies.

\begin{tabular}{cc}
\hline$\eta_{a, \text { pred }}$ & $\eta_{e, \text { meas }}$ \\
\hline 0.25 & 0.21 \\
\hline
\end{tabular}

One can see that the predicted aerodynamic efficiency by the present computational procedure is in a rather reasonable relationship with the measured efficiency of the wind turbine plant for the conversion of the wind energy to the electrical power (Table 1).

\section{Conclusions}

The aerodynamics of a small wind turbine is analyzed by means of experiments and numerical predictions. In the latter, an unsteady $3 \mathrm{D}$ formulation is used, modelling the flow turbulence by an IDDES approach in combination with a transitional SST model. A good agreement between the experiments and calculations is observed.

We gratefully acknowledge the financial support by the German Federal Ministry of Economy of Technology for this research project.

\section{References}

1. A. C. Benim, A. Nahavandi, K. J. Syed, Progress in Computational Fluid Dynamics, 5, 8, pp.444-454 (2005)

2. A. C. Benim, M. P. Escudier, A. Nahavandi, A. K. Nickson, K. J. Syed, F. Joos, International Journal of Numerical Methods for Heat \& Fluid Flow, 20, 3, pp.348-370 (2010)

3. A. C. Benim, H. Chattopadhyay, A. Nahavandi, International Journal of Thermal Sciences, 50, 10, pp. 1973-1983 (2011)

4. A. Chehouri, R. Younes, A. Ilinca, J. Perron, Appl. Engy 142, pp.361-388 (2015)

5. X. M. Chen, R. Agarwal, J. Aircraft, 49, pp.622-629 (2012)

6. A. F. P. Ribeiro, A. M. Awruch, H. M., Gomes, Applied Math. Modelling, 36, pp.4898-4907 (2012)

7. Y. P. Ju, C. H. Zhang, J. Power, 226, pp.245-261 (2012)

8. www.ansys.com

9. A. C. Benim, M. Geiger, S. Doehler, M. Schoenenberger, H. Roemer, Modelling the flow in the exhaust hood of steam turbines under consideration of turbine-exhaust hood interaction, in: Proceed. 1st European. Conf. Turbomachinery Fluid Dynamic and Thermodynamic Aspects: Computational. Methods, Erlangen, Germany, March 1-3, 1995, Book Series: VDI Ber., Vol.1185, pp.343-357 (VDI Verlag, Duesseldorf, 1995)

10. A. C. Benim, D. Brillert, M. Cagan, ASME Paper No. GT2004-54151, 4, pp. 453-460, (2004)

11. A. C. Benim. M. Diederich, B. Pfeiffelmann, Computation, 6, 2, 34 (2018)
12. M. S. Gritskevich, A. V. Garbaruk, J. Schutze, F. R. Menter, Flow, Turbulence, Combustion, 88, pp.431449 (2012)

13. F. Menter, T. Esch, S. Kubacki, "Transition modelling based on local variables", Engineering Turbulence Modeling and Experiments 5, W. Rodi, N. Fueye, Eds., pp.555-564 (Elsevier, Amsterdam 2002) pp.555-564.

14. P. Oclon, S. Lopata, M. Nowak, A. C. Benim, Progress in Computational Fluid Dynamics, 15, 5, pp.290-306 (2015)

15. F. R. Menter, AIAA Journal, 32, pp. 1598-1605 (1994)

16. A. C. Benim, A. Nahavandi, "A computational analysis of turbulent swirling flows", in: K. Hanjalic, Y. Nagano. M. J. Tummers (Eds.) Turbulence, Heat and Mass Transfer, vol. 4, pp.715722 (Begell House, Danbury, Connecticut, 2003)

17. A. C. Benim, M. Cagan, D. Gunes, International Journal of Thermal Sciences, 43, 8, pp.725-732 (2004)

18. A. C. Benim, M. Cagan, A. Nahavandi, E. Pasqualotto, RANS predictions of turbulent flow past a circular cylinder over the critical regime, (Proc. $5^{\text {th }}$ IASME/WSEAS International Conference on Fluid Mechanics and Aerodynamics, Athens, Greece, pp.232-237, 2007)

19. A. C. Benim, K. Ozkan, M. Cagan, D. Gunes, International Journal of Numerical Methods for Heat \& Fluid Flow, 17, 3, pp.284-301 (2007)

20. A. Assmann, A. C. Benim, F. Gül, P. Lux, P. Akhyari, U. Boeken, F. Joos, P. Feindt, A. Lichtenberg, Journal of Biomechanics, 45, 1, pp.156-163 (2012) 